\title{
The Role of Autophagy Dysregulation in Manganese-Induced Dopaminergic Neurodegeneration
}

\author{
Jianbin Zhang $\cdot$ Rui Cao $\cdot$ Tongjian Cai $\cdot$ Michael Aschner • \\ Fang Zhao $\cdot$ Ting Yao $\cdot$ Yaoming Chen $\cdot$ Zipeng Cao $\cdot$ \\ Wenjing Luo $\cdot$ Jingyuan Chen
}

Received: 19 October 2012/Revised: 8 April 2013/Accepted: 9 April 2013/Published online: 19 April 2013

(C) The Author(s) 2013. This article is published with open access at Springerlink.com

\begin{abstract}
The etiological role of dysregulated autophagy in neurodegenerative diseases has been a subject of intense investigation. While manganese $(\mathrm{Mn})$ is known to cause dopaminergic (DAergic) neurodegeneration, it has yet to be determined whether the dysregulation of autophagy plays a role in Mn-induced neuronal injury. In this study, we investigated the effect of Mn on autophagy in a rat model of manganism, a neurodegenerative disease associated with excessive exposure to $\mathrm{Mn}$. After a single intrastriatal injection of Mn, the short- (4-12 h) and long-term (1-28 days) effect of Mn on DAergic neurons and autophagy were examined. Marked reduction in the number of TH-immunoreactive neurons in the substantia nigra pars compacta (SNpc) as well as TH protein expression, and a significant increase of apomorphine-induced rotations were observed in rats after Mn injection. Manganese also induced the downregulation of dopamine levels and $\mathrm{D}_{1}$ dopamine receptor expression. In addition, autophagy was dysregulated and inhibited, as evidenced by increased number of abnormal
\end{abstract}

Jianbin Zhang, Rui Cao, and Tongjian Cai contributed equally to this study.

J. Zhang - R. Cao - T. Cai - F. Zhao - T. Yao - Y. Chen ·

Z. Cao $\cdot$ W. Luo $(\bowtie) \cdot$ J. Chen $(\bowtie)$

Department of Occupational \& Environmental Health and the

Ministry of Education Key Lab of Hazard Assessment and

Control in Special Operational Environment, School of Public

Health, Fourth Military Medical University, 169 Changlexi

Road, Xi' an 710032, China

e-mail: luowenj@fmmu.edu.cn

J. Chen

e-mail: jy_chen@fmmu.edu.cn

M. Aschner

Department of Pediatrics, Vanderbilt University Medical Center,

Nashville, TN, USA lysosomes, decreased protein expression of Beclin1, and decreased ratio of microtubule-associated protein 1 light chain 3 (LC3) II over LC3 I, concomitant with activated mammalian target of rapamycin (mTOR)/p70 ribosomal protein S6 kinase (p70s6k) signaling. In contrast, in the early phase of $\mathrm{Mn}$ exposure, the level of autophagy was not be suppressed but compensatorily activated. Although the morphology of the DAergic neuron was intact in the early phase, Mn caused a significant decrease in TH-immunoreactivity and a significant increase in apomorphine-induced rotations in the presence of wortmannin, an inhibitor of autophagy. Taken together, these results demonstrate, for the first time, that autophagy may play a protective role against $\mathrm{Mn}$-induced neuronal damage, whilst dysregulation of autophagy at later phases may mediate DAergic neurodegeneration.

Keywords Manganese $\cdot$ Autophagy $\cdot$ Dopaminergic neuron $\cdot$ Beclin 1

$\begin{array}{ll}\text { Abbreviations } \\ \text { CNS } & \text { Central nervous system } \\ \text { CPu } & \text { Caudate-putamen complex } \\ \text { LC3 } & \text { Microtubule-associated protein 1 light chain } 3 \\ \text { Mn } & \text { Manganese } \\ \text { mTOR } & \text { Mammalian target of rapamycin } \\ \text { p70s6k } & \text { p70 Ribosomal protein S6 kinase } \\ \text { PD } & \text { Parkinson's disease } \\ \text { SN } & \text { Substantia nigra } \\ \text { TH } & \text { Tyrosine hydroxylase }\end{array}$

\section{Introduction}

As one of the most abundant element in the earth's crust, $\mathrm{Mn}$ is an essential element for humans, animals, and plants, and 
is required for growth, development, and maintenance of health. Mn is necessary for a variety of metabolic functions, including lipid, protein, and carbohydrate metabolism, and it serves as a cofactor for various enzymes, including the antioxidant enzyme superoxide dismutase (SOD), as well as enzymes involved in neurotransmitter synthesis and metabolism (Carl et al. 1993; Keen et al. 2000; Johnson and Giulivi 2005; Aschner et al. 2007). However, exposure to high levels of Mn may lead to a neurological disorder that shares many similarities with Parkinson's disease (PD), and is referred to as manganism. Within the central nervous system (CNS), exposure to high levels of $\mathrm{Mn}$ in occupational or environmental settings or disease conditions is accompanied by $\mathrm{Mn}$ accumulation in specific brain regions that are highly sensitive to oxidative injury, including the global pallidus (GP), striatum (STR) and substantia nigra (SN) (Newland et al. 1989; McKinney et al. 2004; Benedetto et al. 2010). DAergic neurodegeneration in the $\mathrm{SN}$ has been reported in manganism (Levy and Nassetta 2003). The disorder was firstly reported by John Couper in 1837 in five men working in a Mn ore crushing plant in France, characterized by muscle weakness, limb tremor, whispering speech, salivation, and a bent posture. The most frequent cause of $\mathrm{Mn}$ neurotoxicity is believed to be chronic occupational exposure to high levels of inhalable manganese $\left(>1-5 \mathrm{mg} \mathrm{Mn} / \mathrm{m}^{3}\right)$, which is commonly associated with occupations, such as Mn mining and smelting, battery manufacturing, and steel production (Santamaria et al. 2007) .

Autophagy is a general term referring to pathways by which cytoplasmic materials, including soluble macromolecules and organelles, are delivered to lysosomes for degradation, thus eliminating defective cell structures (Mizushima et al. 2010). Accordingly, imbalance in autophagy has been implicated in several diseased states. Recent studies reveal the degradation of disease-related mutant proteins is highly dependent on autophagy, in addition to the ubiquitin-proteasome system ( $\mathrm{Li}$ and $\mathrm{Li}$ 2011). Examples include extended polyglutamine-containing proteins that cause various neurodegenerative diseases, such as Huntington's disease and spinocerebellar ataxia, and mutant forms of $\alpha$-synuclein that causes familial PD (Zhao et al. 2009). Dysregulation of autophagy has been linked to several neurodegenerative diseases (Jung et al. 2010; Alirezaei et al. 2011, Chen and Klionsky 2011; Fan and Weiss 2011). In contrast, up-regulation of autophagy has been found to afford neuroprotection, delaying, or ameliorating these disorders (Alirezaei et al. 2011). However, the role of dysregulated autophagy in mediating Mn-induced neurotoxicity has yet to be addressed. In the present study, we investigated the effect of Mn on autophagy and the role of its dysregulation in Mn-induced DAergic neuronal damage.

\section{Materials and Methods}

Materials and Reagents

Polyclonal anti-tyrosine hydroxylase antibody (TH) was obtained from Chemicon (Temecula, CA, USA). Neu-N antibody was purchased from Santa Cruz Biotechnology (Santa Cruz, CA, USA). Other chemicals and reagents were purchased from Cell Signaling Technology (Inc., Danvers, MA, USA).

Animals and Treatment

All procedures involving animals were carried out in strict accordance with the international standards of animal care guidelines and were approved by the institutional animal care and use committee of Fourth Military Medical University (Permit Number:12002). Male Sprague-Dawley rats (180-210 g) were purchased from the Experimental Animal Center of Fourth Military Medical University. They were maintained in a standard environmental condition and fed with a standard pellet diet and water ad libitum. The rats were housed in stainless steel cages in a room kept at $22 \pm 1{ }^{\circ} \mathrm{C}$ with a 12-h light/12-h dark cycle.

Rats were injected with $\mathrm{Mn}$ as we previously described (Zhao et al. 2009). In brief, rats were anaesthetized with sodium pentobarbital (60 mg/kg ip) and placed in a stereotaxic frame with the nose bar set at $-2.4 \mathrm{~mm}$. For manganese intoxication, rats were stereotaxically injected in the right striatum with $1 \mu \mathrm{l}$ $\mathrm{MnCl}_{2} \cdot 4 \mathrm{H}_{2} \mathrm{O}(1 \mathrm{~mol} / \mathrm{L})$ or $0.9 \% \mathrm{NaCl}$. The following stereotaxic co-ordinates were used: $1 \mathrm{~mm}$ anterior-posterior, $3 \mathrm{~mm}$ lateral, $4.5 \mathrm{~mm}$ ventral to the dura. The injections were slowly infused over $1 \mathrm{~min}$ to avoid tissue damage and the needle remained in situ for additional $8 \mathrm{~min}$ prior to its withdrawal. Wortmannin $(100 \mathrm{mg} / \mathrm{kg})$ treated rats were i.p. injected $30 \mathrm{~min}$ prior to the Mn or saline injection. For long-term treatments, observations, and analyses were conducted at 1, 7, 14, and 28 days postinjections. For short-term treatments, observations, and analyses were conducted 4,8 , and $12 \mathrm{~h}$ post injection. At the end of the experiments, rats were sacrificed and the brains were collected for morphological and biochemical analyses.

\section{Apomorphine-Induced Rotations}

Five minutes after the i.p. injection of $0.6 \mathrm{mg} / \mathrm{kg}$ apomorphine, each rat was placed in a chamber $\left(1 \times 1 \mathrm{~m}^{2}\right)$ and the rotational asymmetry (ipsilateral-contralateral) score was recorded for $30 \mathrm{~min}$ following the injection, as previously described (Mandel 2000).

\section{Histological Observation}

Immediately upon removal, the brains were fixed in $10 \%$ buffered formaldehyde, and processed for histological 
examination according to conventional methods, followed by hematoxylin and eosin (H\&E) staining.

\section{Immunostaining}

Immunostaining was carried out as we previously reported (Zhao et al. 2009). In brief, rats were cordially perfused under deep anesthesia with 150-200 $\mathrm{ml}$ of $4 \%$ paraformaldehyde in phosphate buffer, $\mathrm{pH}$ 7.4. Then brains were removed, and cryoprotection was carried out in $25 \%$ sucrose phosphate buffer, $\mathrm{pH}$ 7.4. Next, the brains were frozen at $-20^{\circ} \mathrm{C}$, and serial sections $(10 \mu \mathrm{m})$ were cut and mounted on glass slides. Nonspecific antibody-binding sites were blocked with $1 \%$ bovine serum albumin (BSA; Sigma-Aldrich, St Louis, MO) in PBS, after which slides were incubated with primary antibodies. The anti-TH antibody was used to identify DAergic neurons by conventional immunocytochemistry techniques. Neurons were identified by immunocytochemistry with an anti Neu-N antibody. The sections were visualized using a mixture of fluorescein isothiocyanate (FITC)-conjugated anti-mouse (diluted 1:400; Sigma) and Cy3-conjugated antirabbit (diluted 1:600; Sigma) antibodies. Sections were examined with a FV300 laser scanning microscope (Olympus, Tokyo, Japan).

The total number of TH-positive DAergic neurons and Neu$\mathrm{N}$-positive neurons in substantia nigra pars compacta $(\mathrm{SNpc})$ were counted in various groups of animals at $8 \mathrm{~h}, 1,7,14$, and 28 days after the treatment using the following method as described previously (Iravani et al. 2005). The number of tyrosine hydroxylase-immunoreactive (TH-ir) neurons at the level of the third nerve was obtained by manually counting the total TH-ir neurons from three to seven adjacent sections, and divided by the number of sections. Based on the counting of DAergic neurons throughout the SNpc at regular $100-\mu \mathrm{m}$ intervals, it was previously shown that the third nerve rootlets provide a reliable anatomical landmark at which the extent of cell loss can be accurately assessed and the extent of cell loss at this point is reflective of cell loss throughout the entire structure (Iravani et al. 2002). The extent of dopamine neuronal loss was estimated by counting the number of TH-ir SNpc neurons at the level of the third nerve rootlets on the lesioned side compared with that of control rats. All cells that appeared severely deformed were excluded from the count.

\section{Transmission Electron Microscopy (TEM)}

TEM was conducted as previously reported (Ye et al. 2010). In brief, at the end of the experiments, brains were collected and fixed in $2 \%$ glutaraldehyde in 0.1 M PBS (pH 7.4) for $2 \mathrm{~h}$ at $4{ }^{\circ} \mathrm{C}$. Subsequently, they were post-fixed in $1 \%$ osmium tetroxide in 0.1 M PBS (pH 7.4) for $2 \mathrm{~h}$ at $4{ }^{\circ} \mathrm{C}$. Next, the SN tissue was dissected out $\left(1 \mathrm{~mm}^{3}\right)$ and sequentially processed in $1 \%$ osmium tetroxide, dehydrated in ascending ethanol solutions ranging from 20 to $100 \%$, and embedded in E-pon812. Ultrathin sections ( $80 \mathrm{~nm}$ ) were impregnated in $2 \%$ uranyl acetate and Reynold's lead citrate. Sections were viewed with transmission electron microscope (JEM-2000EX, Japan).

\section{Western Blotting}

Western blotting was conducted as previously described (Wang et al. 2011). In brief, brains were incubated on ice with lysis buffer and centrifuged at $20,000 \times g$. The supernatant was collected and protein concentrations were determined with the Pierce Bicinchoninic acid (BCA) Protein Assay Kit (Thermo). Next, the supernatant was mixed with equal volume of sample buffer and the mixture was boiled for 5 min and centrifuged for $10 \mathrm{~min}$ at $10,000 \times g$. Proteins were separated by SDS-PAGE on 5-12\% polyacrylamide gels, and transferred to nitrocellulose membranes (Millipore, Billerica, MA, USA). After blocking for $1 \mathrm{~h}$ with $5 \%$ skimmed milk in TBS buffer (10 $\mathrm{mM}$ Tris, $150 \mathrm{mM} \mathrm{NaCl}$ ), the membranes were probed with primary antibodies, including rabbit anti-Human $\mathrm{TH}$ polyclonal antibody (1:1,000 dilution, Chemicon, Temecula, CA, USA), mouse anti- $\beta$-actin monoclonal antibody $(1: 1,000$ dilution, Santa Cruz Biotechnology, CA, USA), rabbit antiBeclin 1 polyclonal antibody (1:1,000, Cell Signaling Technology, Inc., Danvers, MA, USA), anti-D $\mathrm{D}_{1}$ dopamine receptor polyclonal antibody (1:1,000 dilution, Sigma-aldrich, USA), rabbit anti-LC3 antibody (1:500, Cell Signaling Technology, Inc., Danvers, MA, USA), rabbit anti-p70S6K antibody (1:1,000, Cell Signaling Technology, Inc., Danvers, MA, USA), rabbit anti-phospho p70S6K antibody (1:1,000, Cell Signaling Technology, Inc., Danvers, MA, USA), rabbit antimTOR antibody (1:1,000, Cell Signaling Technology, Inc., Danvers, MA, USA), rabbit anti-phospho mTOR antibody (1:1,000, Cell Signaling Technology, Inc., Danvers, MA, USA) at $4{ }^{\circ} \mathrm{C}$ overnight. Next, the membranes were washed four times, $15 \mathrm{~min}$ each, with TBST buffer $(10 \mathrm{mM}$ Tris, $150 \mathrm{mM}$ $\mathrm{NaCl}$, and $0.1 \%$ Tween-20) and incubated for $30 \mathrm{~min}$ at $37{ }^{\circ} \mathrm{C}$ with appropriate HRP-conjugated secondary antibodies. The protein bands were visualized with chemiluminescent reagents following the manufacturer's instructions, and exposed to Hyperfilm-ECL (Amersham). Densitometry analysis of band intensity was performed using Image $\mathbf{J}$ software.

\section{Enzyme-Linked Immunoassay (ELISA)}

Rats were sacrificed and brain tissues were quickly removed, frozen in liquid nitrogen and stored at $-80{ }^{\circ} \mathrm{C}$ for posterior biochemical analysis. The levels of DA were measured by ELISA according to the manufacturer's (Xi Tang, Biotech, Shanghai, China) instructions. A $50 \mathrm{mg}$ portion of the homogenate was diluted in $500 \mu \mathrm{l}$ normal saline $(0.9 \%)$ for detection. The DA in supernatant fluid was assayed by using the ELISA kit (Xi Tang, Biotech, Shanghai, China) after 
centrifugation of homogenized tissue for $10 \mathrm{~min}$ at $14,000 \times g$ at $4{ }^{\circ} \mathrm{C}$. Dispensed antigen standards and samples were added to each well of 96-well plates precoated with primary antibodies. After adding biotin conjugate reagent and enzyme conjugate reagent into each well, the plates were incubated at $37{ }^{\circ} \mathrm{C}$ for $30 \mathrm{~min}$. Then the plates were rinsed five times with distilled water. Within $30 \mathrm{~min}$ of the chromogenic reaction, the absorbance was measured at $450 \mathrm{~nm}$ using a microtiter plate reader (TECAN, Swiss).

\section{Statistical Analysis}

Results were expressed as the mean \pm SD and were analyzed by one-way analysis of variance (ANOVA) followed
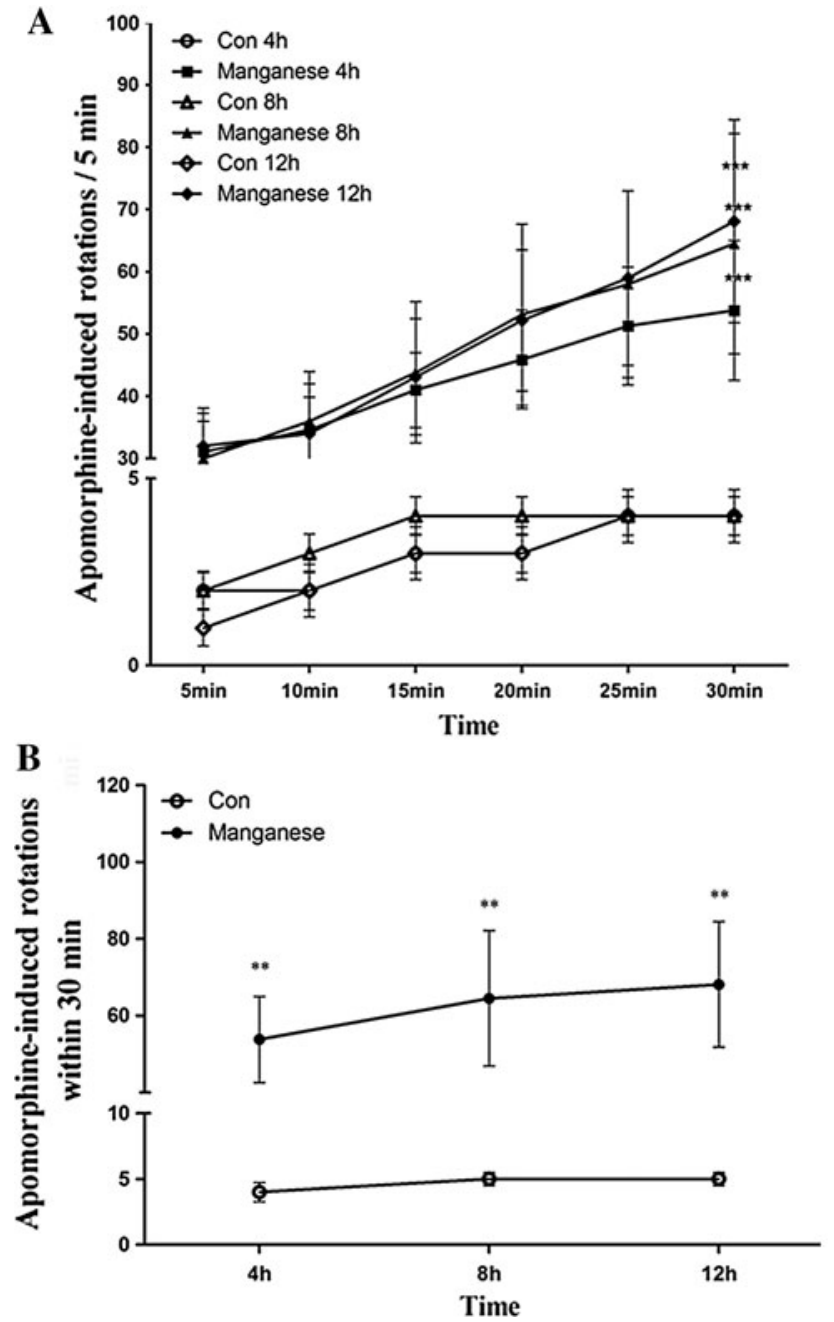

Fig. 1 The effect of manganese on apomorphine-induced rotations. Different time points after manganese administration, rats were dosed with i.p. injection of $0.6 \mathrm{mg} / \mathrm{kg}$ apomorphine, and then placed in a chamber $\left(1 \times 1 \mathrm{~m}^{2}\right)$ in a testing room and their rotational asymmetry (ipsilateral-contralateral) score was monitored for $30 \mathrm{~min}(n=10)$. a, c Rotational behavior induced by apomorphine was assessed after short-term $(4,8$, and $12 \mathrm{~h})$ and long-term $(1,7,14$, and 28 days) periods. The number of full $360^{\circ}$ rotations in the ipsilateral direction by a SNK- $q$ test for multiple comparisons. Student $t$ test was used for two group comparisons. All analyses were performed with SPSS 16.0 software. Data were considered statistically significant at $p<0.05$.

\section{Results}

Effect of Mn on Apomorphine-Induced Rotation

Previous studies have shown that if the DAergic neurons are damaged in SNc, there will be abnormal behaviors. Apomorphine-induced abnormal rotational behavior after Mn injection was evaluated as a surrogate of DAergic
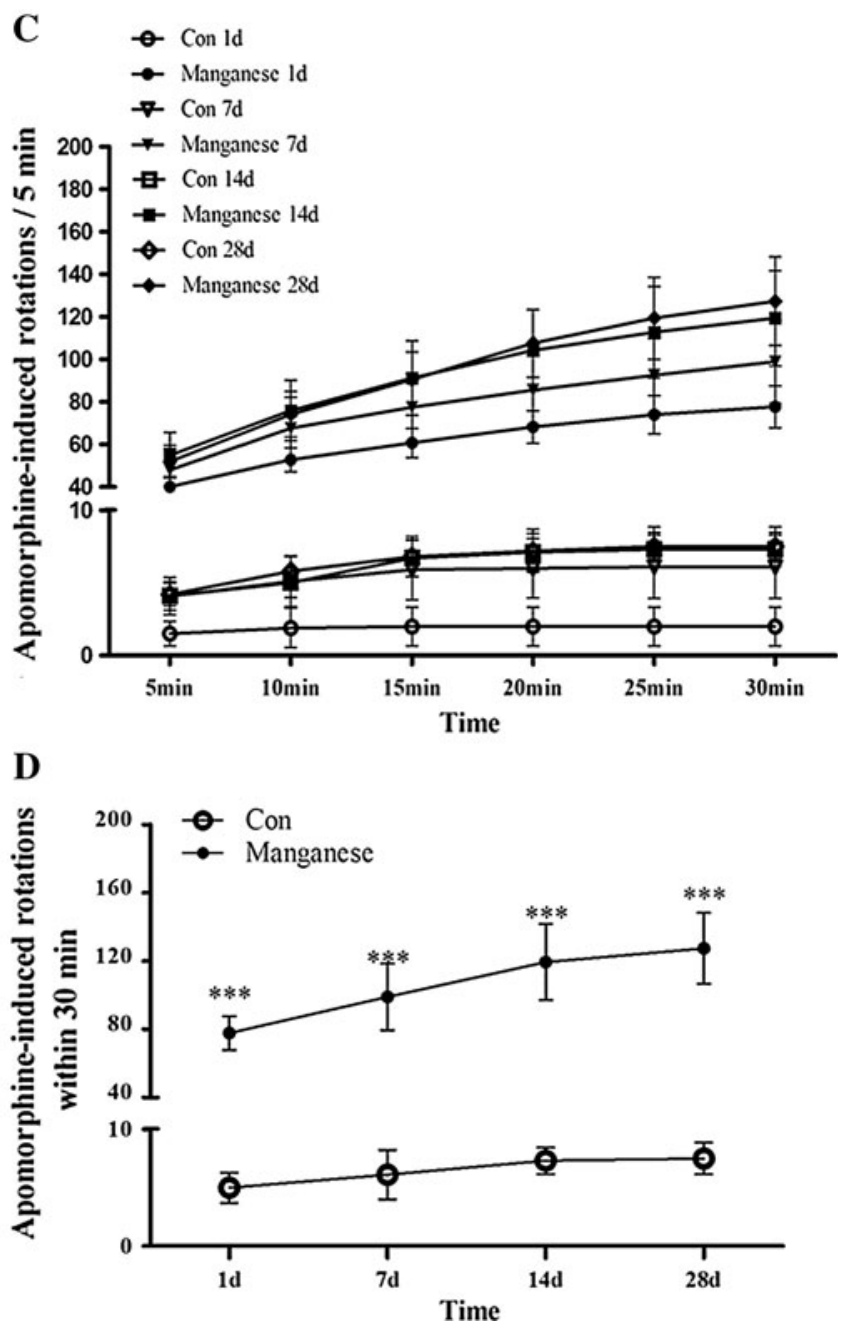

was counted for $30 \mathrm{~min}$ after the administration of apomorphine. Significance (Bonferroni/Dunn post hoc comparisons after ANOVA): $* p<0.05, * * p<0.01$ versus the vehicle control at each time point. $\mathbf{b}, \mathbf{d}$ Time-course of changes in the number of apomorphine-induced ipsilateral rotations at different time points in rats injected with vehicle control, or $\mathrm{Mn}$, or wortmannin. Graphs show mean $\pm \mathrm{SD}$. $* p<0.05, * * p<0.01$, compared with respective control. Student $t$ test was used for two group comparisons 
neuronal integrity (Ungerstedt 1971). In order to detect the damage after Mn exposure, we observed apomorphineinduced rotational behavior. As shown in Fig. 1, apomorphine-induced rotations were significantly increased after that rats were exposed to $\mathrm{Mn}$ for short-term [4, 8, and $12 \mathrm{~h}$ post injection (Fig. 1a, b)] and long-term [1, 7, 14, and 28 days post injection (Fig. 1c, d)] periods.

\section{Effect of Mn on Substantia Nigral DAergic Neurons}

Histological evaluation was conducted to observe the changes in the substantia nigra pars compacta (Fig. 2A). Immunostaining was performed with antibodies against $\mathrm{TH}$ and Neu-N. As shown in Fig. 2B, no obvious change of TH-immunoreactivity was observed at $8 \mathrm{~h}$ post intrastriatal Mn injection. However, from 1 day after intrastriatal $\mathrm{Mn}$ injection, there were significant difference in TH-immunoreactivity compared with that of control group (Fig. 2C). Consistent with this effect, the protein expression of TH unaltered 4, 8 and $12 \mathrm{~h}$ post-Mn injection (Fig. 3a), but 1 day after Mn injection, TH protein levels in the SNc were decreased mildly, and 7-28 days after Mn injection, TH protein levels were decreased significantly, compared with that of control group (Fig. 3c, d).
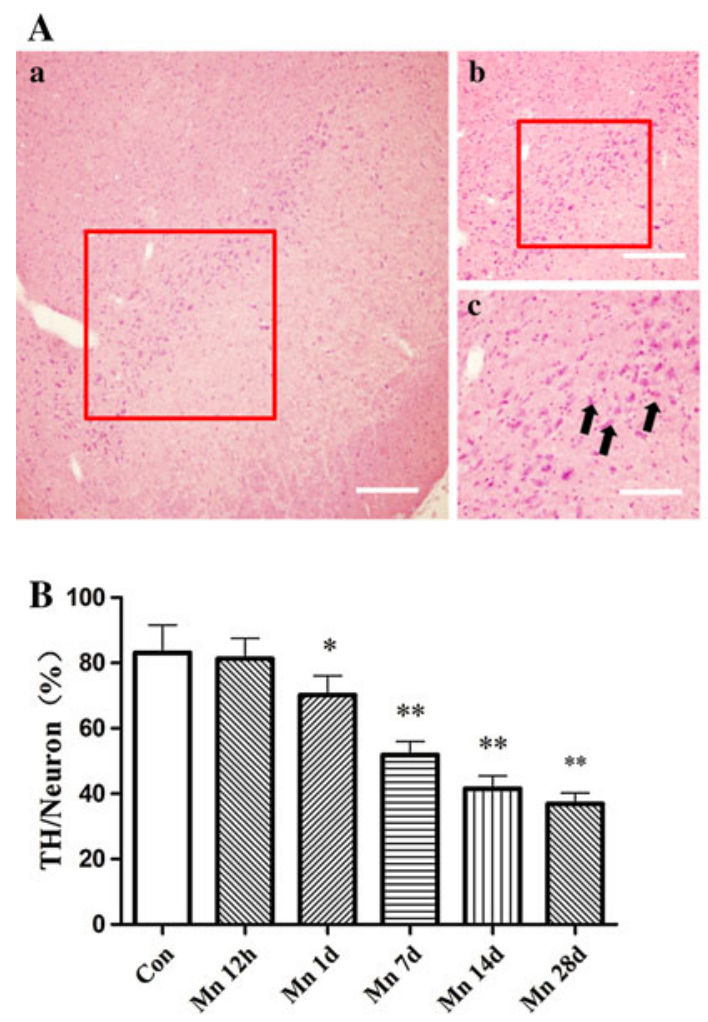

Fig. 2 The effect of manganese on DAergic neurons in immunofluorescence. $8 \mathrm{~h}, 1,7,14$, and 28 days after manganese administration, immunofluorescence was conducted to measure $\mathrm{TH}$-immunoreactivity and TH expression. A Location of substantia nigra pars compacta (SNpc). a Scale bar indicates $1,000 \mu \mathrm{m}$; b Scale bar indicates
The content of dopamine was determined by ELISA. As shown in Fig. 3i, as early as $4 \mathrm{~h}$ after intrastriatal $\mathrm{Mn}$ injection, there was significant difference in dopamine levels compared with controls. Moreover, the dopamine receptor protein level in the SNc decreased mildly 4, 8, $12 \mathrm{~h}$ after Mn injection, but significantly 1, 7, 14, 28 days after Mn injection, compared with that of control group (Fig. 3e, g).

\section{Effect of Manganese on Autophagy}

To evaluate the effect of Mn on autophagy, TEM and Western blotting studies were carried out. As shown in Fig. 4A, the number of autophagosome (the product of fusion of autophagic vacuole lysosome) in Mn-injected rats notably increased, concomitantly with slight swollen mitochondria 4 (Fig. 4A-B), 8 (Fig. 4A-C), 12 h(Fig. 4A-D) after the administration. However, TEM showed progressive effect of intrastriatal Mn injection on several morphometric parameters (Fig. 4A, e-h), characterized by increased number of mitochondrial vacuolus, swollen, and broken endoplasmic reticulum, and dysfunctional lysosomes containing high dense particulate materials and decreased autophagic vacuoles in DAergic neurons in the SNpc of Mn-exposed rats.

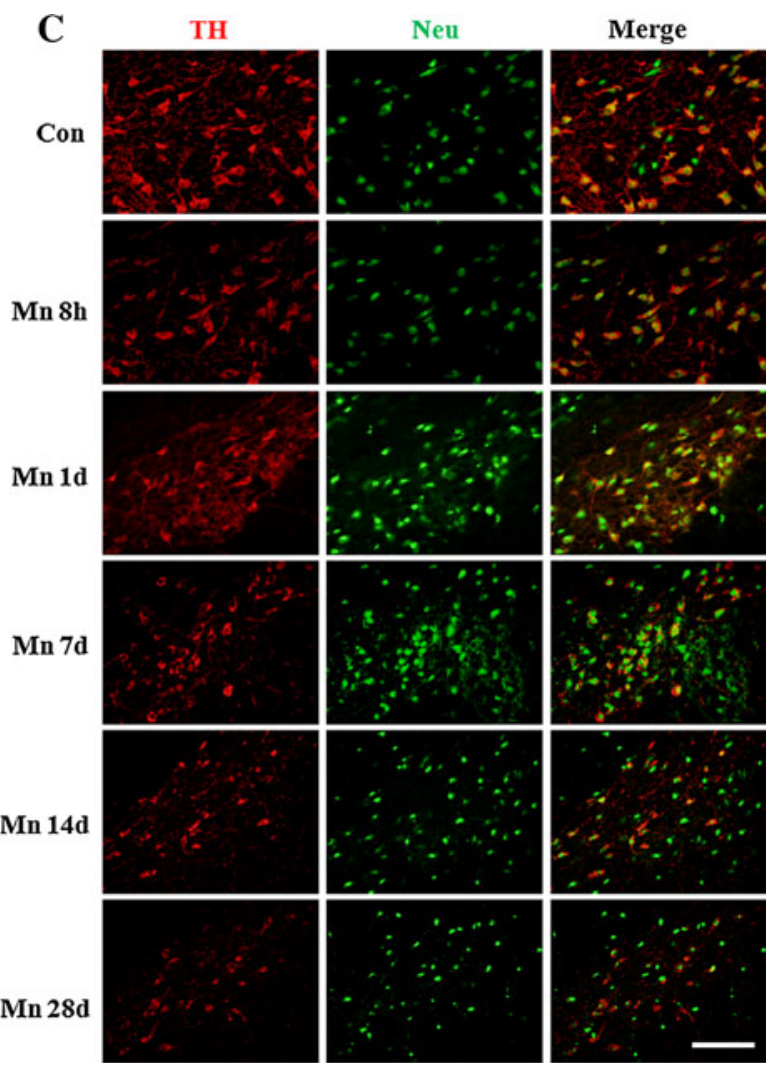

$500 \mu \mathrm{m}$; c Scale bar indicates $200 \mu \mathrm{m}$. B Quantitative analysis of the effect of manganese on DAergic neurons in the ratio of total neurons. ${ }^{*} p<0.05, * * p<0.01$ compared with control groups. C The effect of manganese on TH-immunoreactivity. Scale bar indicates $200 \mu \mathrm{m}$ 
A

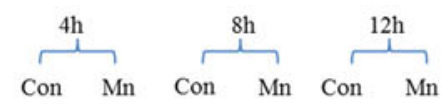

TH

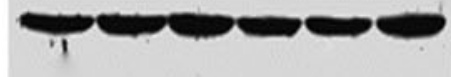

Actin

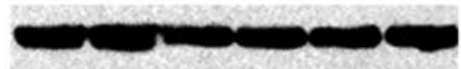

B

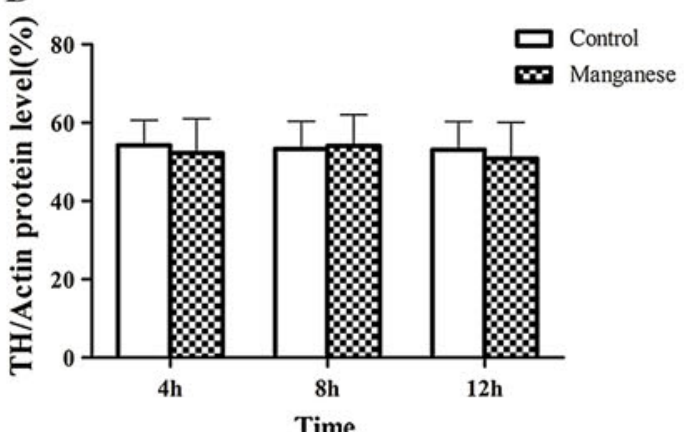

E

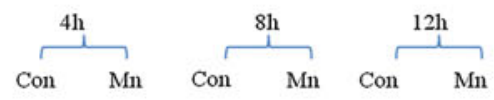

DA receptor
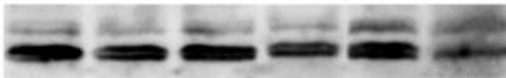

Acti
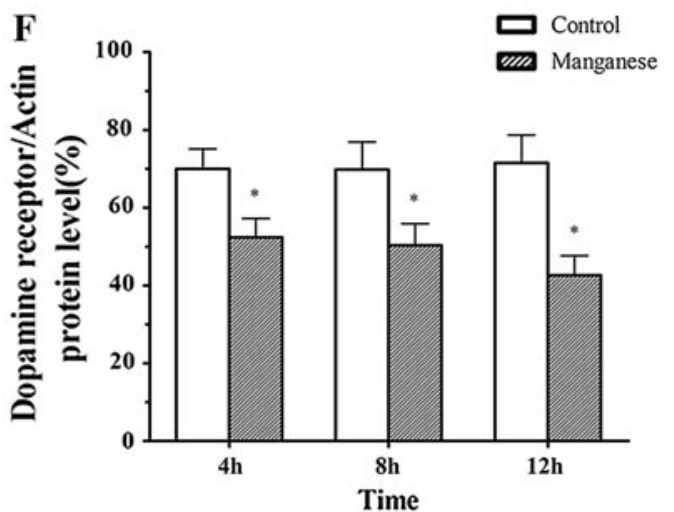

I

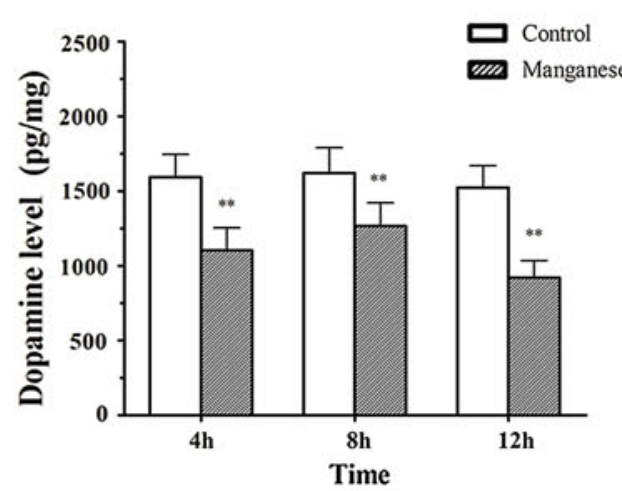

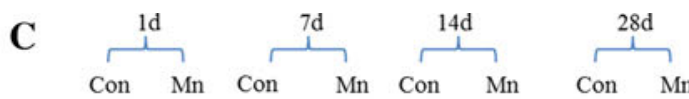

$\mathrm{TH}$

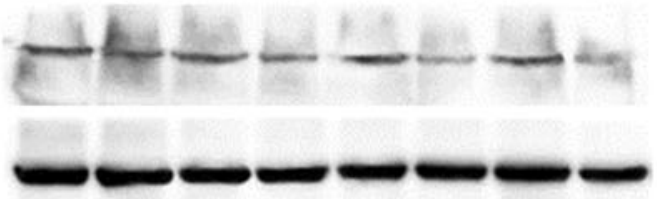

D

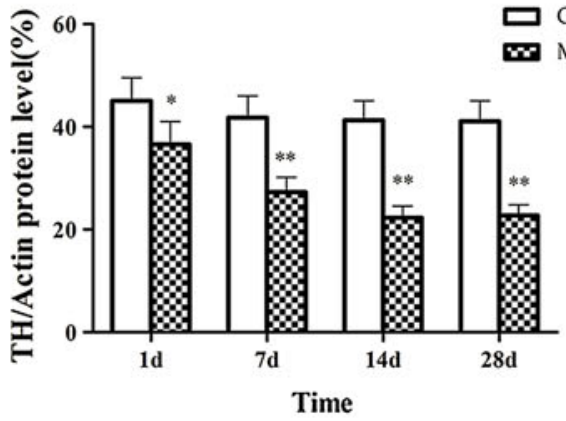

G

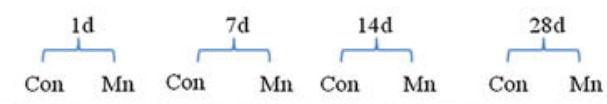

DA receptor
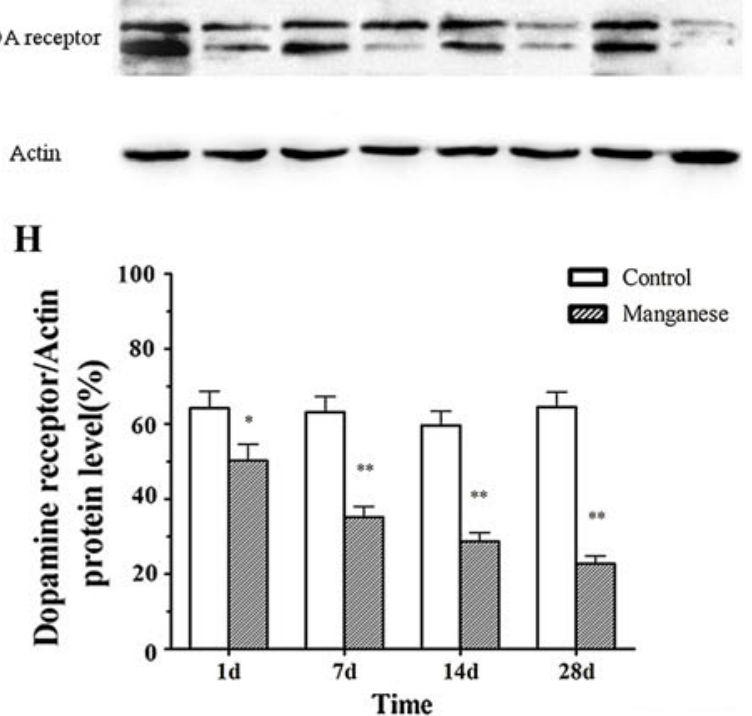

J

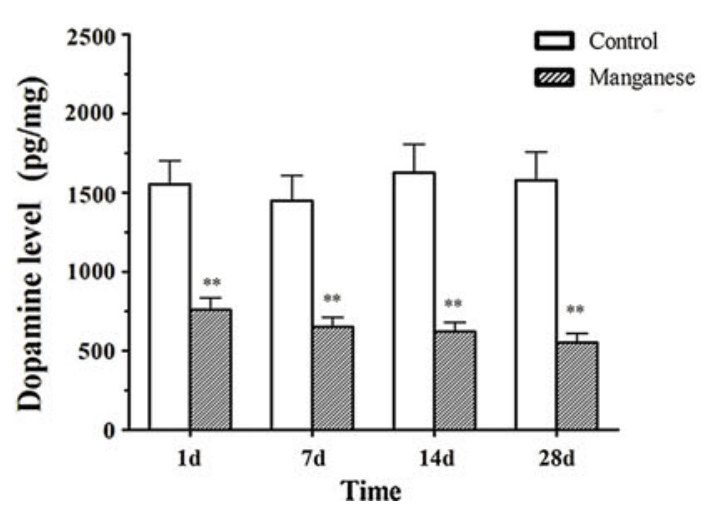


4 Fig. 3 The effect of manganese on DAergic neurons in Western blotting. Short- (4, 8, and $12 \mathrm{~h})$ and long-term $(1,7,14$, and 28 days) after manganese administration, Western blotting was conducted to measure TH expression. a, c Effect of manganese on TH protein expression. $\mathbf{b}, \mathbf{d}$ Densitometry analysis of TH levels relative to $\beta$-actin was performed after three independent experiments. e, $\mathbf{g}$ Effect of manganese on $\mathrm{D}_{1}$ dopamine receptor protein expression. $\mathbf{i}, \mathbf{j}$ Effect of manganese on dopamine levels. $\mathbf{f}, \mathbf{h}$ Densitometry analysis of $\mathrm{D}_{1}$ dopamine receptor levels relative to $\beta$-actin was performed using three independent experiments (mean $\pm \mathrm{SD}$; one-way ANOVA with Newman-Keuls post hoc analysis, $* p<0.05$ and $* * p<0.01$ )

These changes suggest the attenuated rate of autophagy, which is consistent with a former report (Kruger et al. 2011). Additional western blotting experiments established twophase effect of Mn on Beclin-1 and microtubule-associated protein 1 light chain 3 (LC3) protein expression in different phases. As shown in Fig. 4, Beclin 1 protein expression and the ratio of LC3 II to LC3 I were significantly increased by Mn after short-time periods (Fig. 4B), but significantly and time-dependent $(1,7,14$, and 28 days) decreased after long time periods (Fig. 4e). In a word, manganese-induced compensatory autophagy activation in short terms and inhibited autophagy in long terms.

\section{Effect of Mn on Autophagy-Related Signaling Pathway $\mathrm{mTOR} / \mathrm{p} 70 \mathrm{~S} 6 \mathrm{~K}$}

The mammalian target of rapamycin (mTOR) and p70 ribosomal protein S6 kinase (p70S6K) are known to regulate antophagy, and the phosphorylation of these two kinases can suppress autophagy. In order to detect if this signaling pathway is related to the change of autophagy level caused by manganese exposure. The activation of mTOR and p70S6K was measured by western blotting. As shown in Fig. 5a, at short-time points post intrastriatal Mn injection (4, 8, and $12 \mathrm{~h}$ ), the levels of phosphorylated mTOR and p70S6K were significantly reduced, implicating mTOR and p70S6K inhibition in the activation of autophagy. However, with the extension of manganese exposure time, mTOR/p70S6K
A
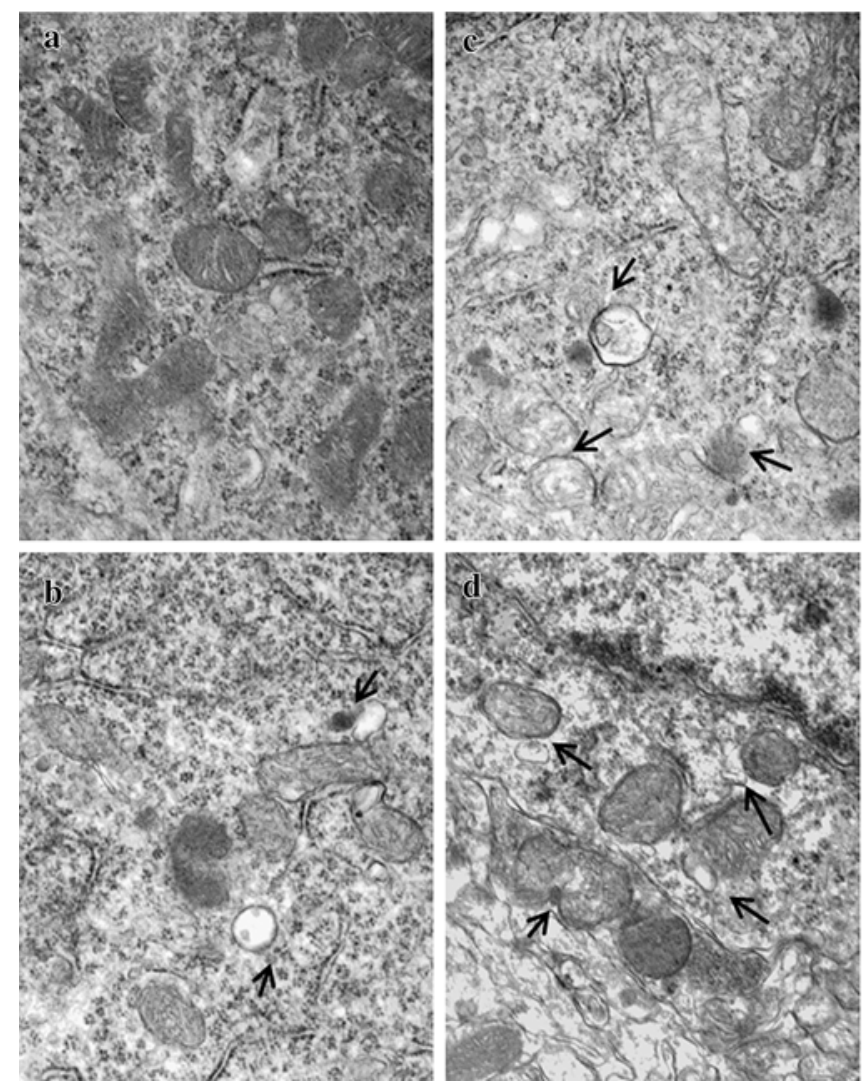
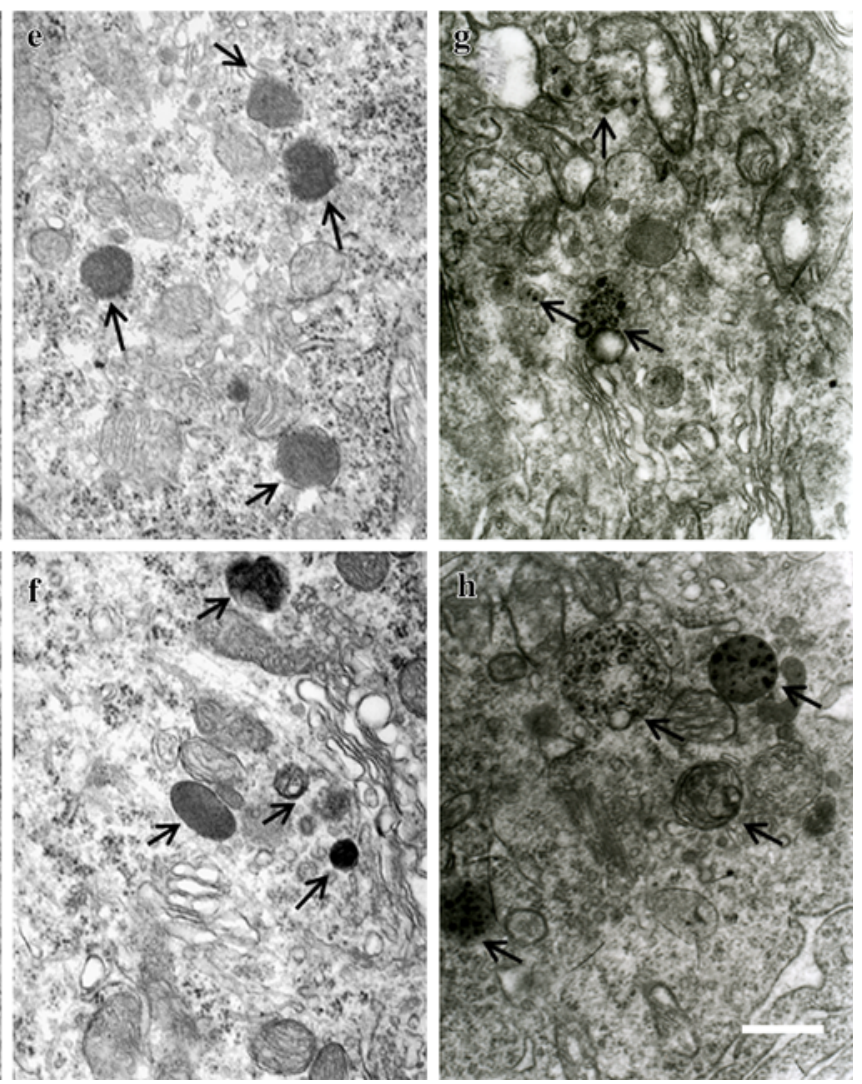

Fig. 4 The effect of Mn on autophagy. Short- (4, 8, and $12 \mathrm{~h})$ and long-term (1, 7, 14, and 28 days) after Mn injection, TEM and Western blotting were conducted to evaluate autophagy. a TEM observation on increased autophagy (a control; b, c, d 4, 8, and $12 \mathrm{~h}$ post $\mathrm{Mn}$ injection) and dysfunctional lysosomes (e-h 1, 7, 14, and 28 days post $\mathrm{Mn}$ injection). Figure $4 \mathbf{A}, \mathbf{b}-\mathbf{d}$ shows that the autophagosomes-containing double membrane increased compared with that of control, Fig. $4 \mathbf{A}, \mathbf{e}-\mathbf{h}$ shows that increased dysfunctional lysosomes-containing dense granules compared with the control. b, e Effect of Mn on protein expression of Beclin 1, LC3 II, and LC3 I. c, $\mathbf{d}, \mathbf{f}, \mathbf{g}$ Densitometry analysis of Beclin 1 protein levels and LC3 II levels relative to LC3 I was performed using three independent experiments. $\beta$-Actin was used as control for protein loading. Above results were obtained after three independent experiments (mean $\pm \mathrm{SD}$; one-way ANOVA with Newman-Keuls post hoc analysis, $* p<0.05$ and $* * p<0.01$ ) 
B
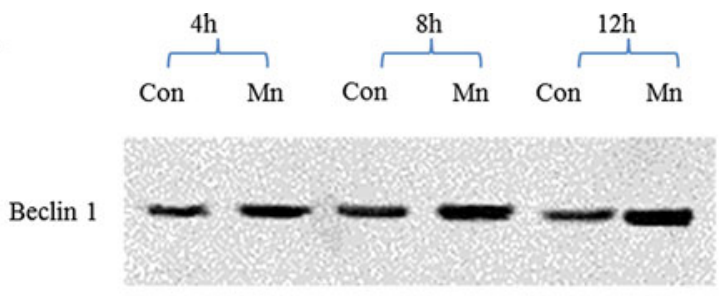

LC3 I

LC3 II

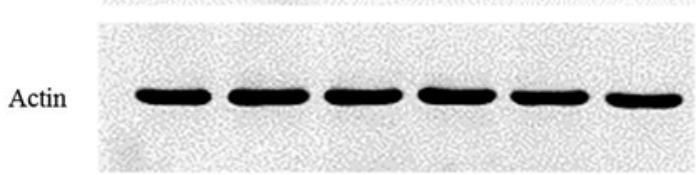

\section{C}

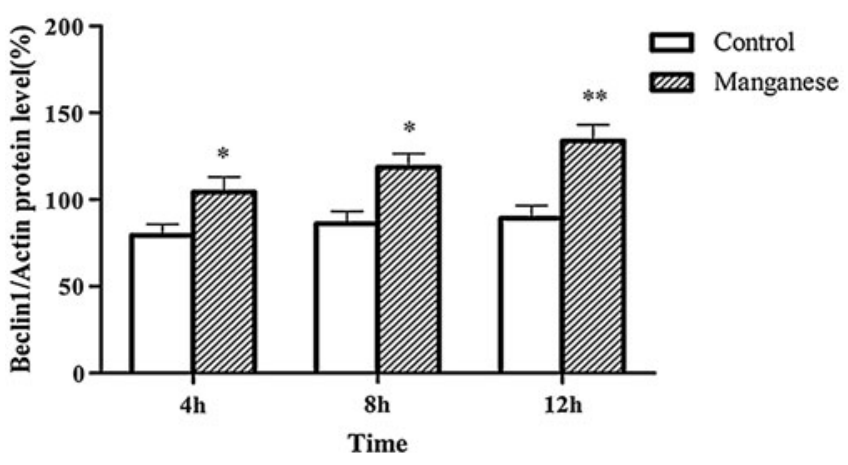

D

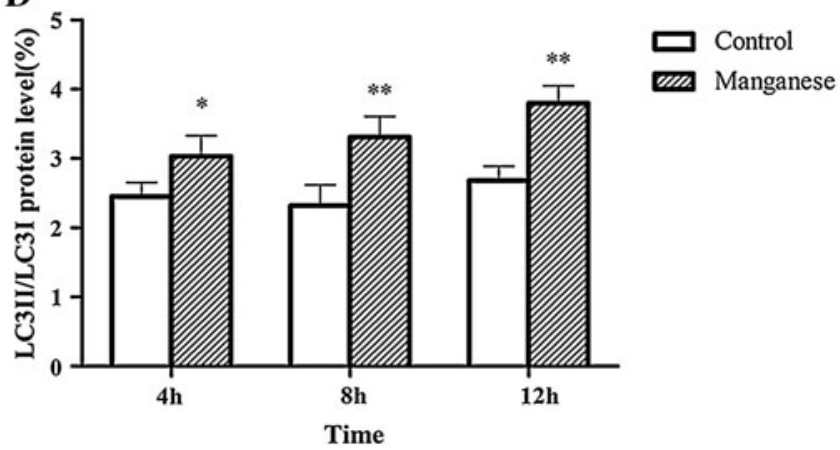

Fig. 4 continued

pathway was significantly and time-dependently $(1,7,14$, and 28 days) activated in Mn-injected animals versus controls (Fig. 5d), which was consistent with the change of autophagy level.

The Inhibition of Autophagy Promoted the Short-Term Neurotoxic Effect of Mn

To further evaluate the effect of autophagy on Mn-induced nigral DAergic neuron damage, we pretreated rats with wotmannin, an inhibitor of phosphatidylinositol 3'-kinase (PI3K III)/protein kinase B (Akt) and frequently used as an autophagy inhibitor, before $\mathrm{Mn}$ exposure. Then we
E
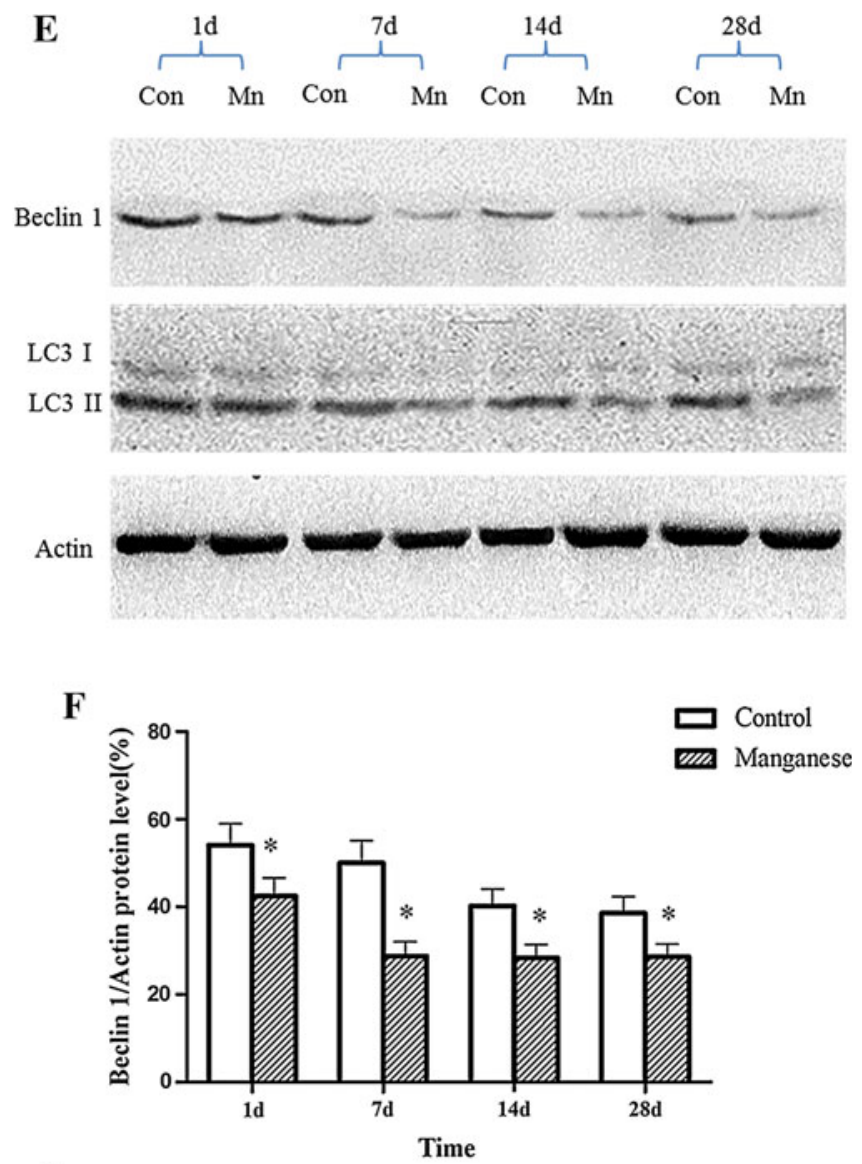

G

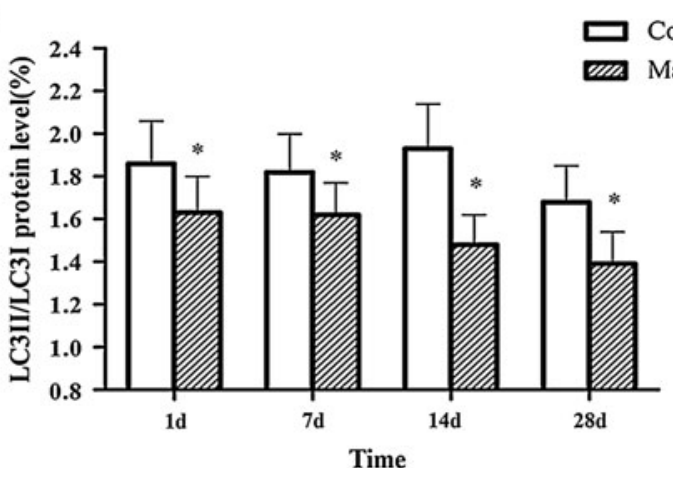

conducted a behavioral observation. Although apomorphine-induced rotation increased compared with that of the control, with the injection of wortmannin, an autophagy inhibitor, more serious apomorphine-induced rotation was observed. Immunostaining results with primary antibodies against $\mathrm{TH}$ and Neu-N showed that the number of $\mathrm{TH}-$ immunoreactive and $\mathrm{TH} / \mathrm{Neu}$ positive cells were indistinguishable between Mn-exposed rats ( $8 \mathrm{~h}$ post injection) and controls (Fig. 6e). Consistent with these results, the protein expression of $\mathrm{TH}$ was unaltered $8 \mathrm{~h}$ post $\mathrm{Mn}$ injection. However, in rats pretreated with wortmannin, Mn led to a significant decrease in the ratio of $\mathrm{TH} / \mathrm{Neu}$ (Fig. 6e) and the TH protein level (Fig. 6g) at $8 \mathrm{~h}$ post-exposure. In addition, 

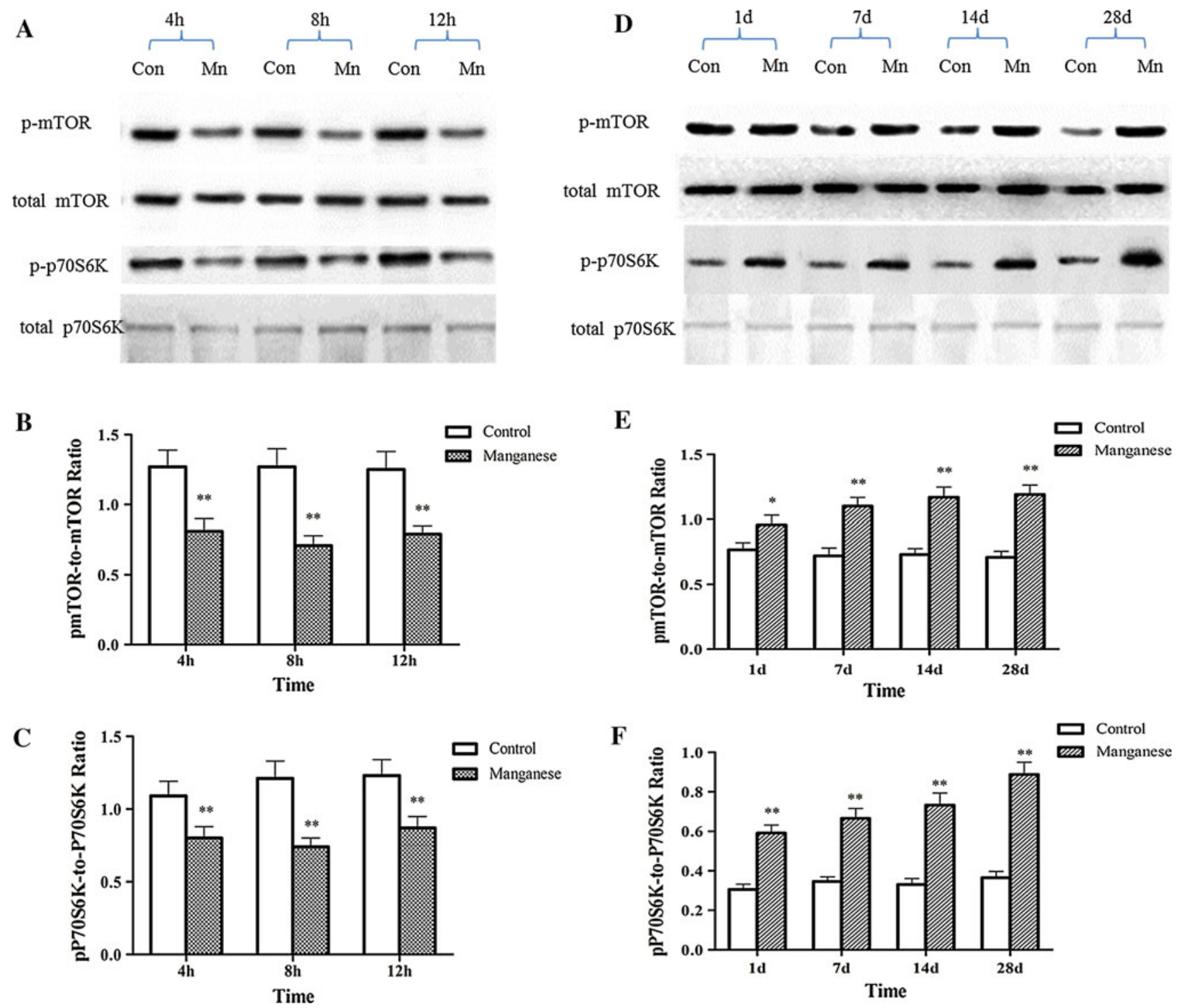

Fig. 5 The effect of Mn on mTOR/p70S6K pathway. Short- (4, 8, and $12 \mathrm{~h})$ and long-term $(1,7,14$, and 28 days) after Mn injection, Western blotting were conducted to evaluate autophagy-related signaling pathway mTOR/p70S6K. a, d Effect of Mn on mTOR/ p70S6K phosphorylation after the short- and long-term exposure. b, c,

wortmannin significantly decreased dopamine and DA receptor levels and promoted Mn-induced behavioral abnormality, as shown by increased apomorphine-induced rotations (Fig. 6d, i). The above results indicate that the activation of autophagy may play an important role in protecting DAergic neurons against Mn-induced toxicity at short-time points post intrastriatal Mn injection.

\section{Discussion}

As a ubiquitous constituent of the environment, $\mathrm{Mn}$ is an essential metal for animal and human health (Hearn et al.
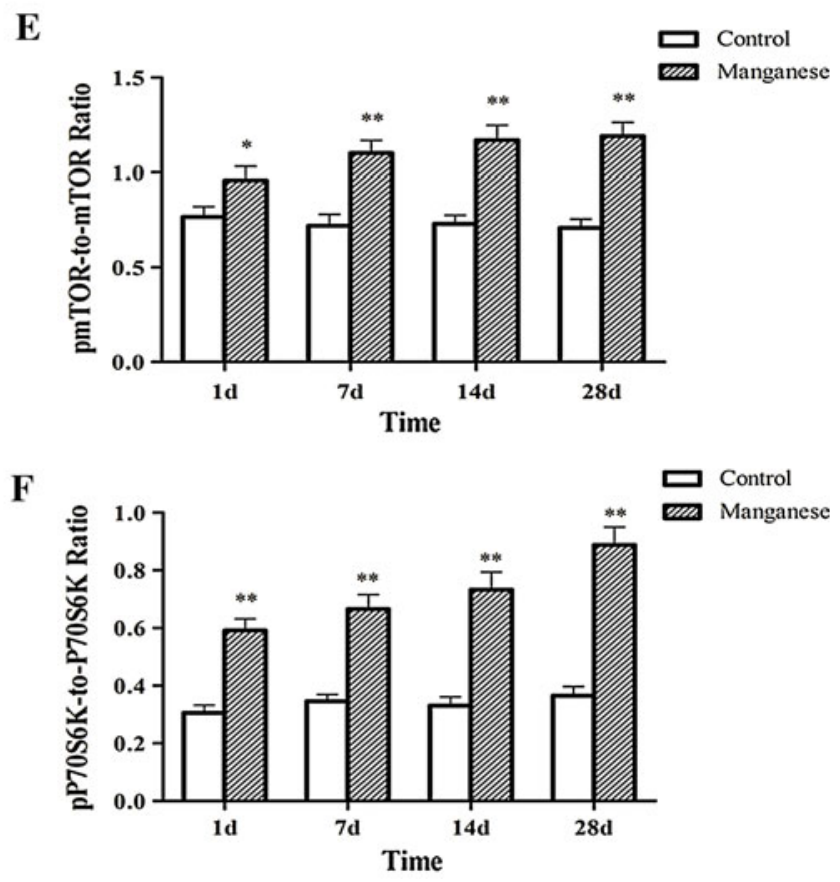

e, and f Densitometry analysis of mTOR/p70S6K phosphorylation relative to total $\mathrm{mTOR} / \mathrm{p} 70 \mathrm{~S} 6 \mathrm{~K}$ levels was performed in three independent experiments (mean $\pm \mathrm{SD}$; one-way ANOVA with Newman-Keuls post hoc analysis, $* p<0.05$ and $* * p<0.01$ )

2003). However, when excessive exposure to Mn occurs, it may cause a neurodegenerative disorder known as "manganism". The disorder is characterized as a Parkinson'slike disease (BS and WJ 2003; Takeda 2003) and has been observed in miners, ferroalloy, and battery manufacture workers, as well as automotive repair workers (Racette et al. 2011). Work by others and us has established the propensity of $\mathrm{Mn}$ to induce DAergic neurodegeneration (Liu et al. 2009; Zhang et al. 2009). However, the mechanisms underlying this effect have yet to be fully clarified. Herein, we examined whether a single unilateral injection of $\mathrm{MnCl}_{2}$ into the caudate-putamen led to dysregulated autophagy and DAergic neurodegeneration. Since Mn was 


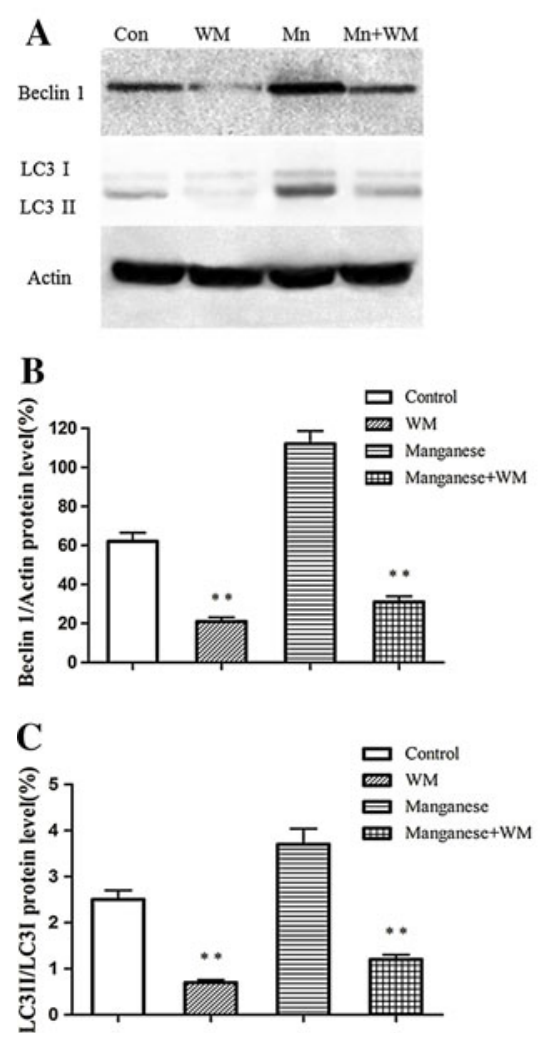

Fig. 6 The inhibition of autophagy promotes the short-term effect of Mn on nigral DAergic neurons and apomorphine-induced rotations. After the pretreatment of wormannin in Mn-exposed rats, immunofluorescence and western blotting were conducted to measure TH-immunoreactivity and the expression of TH protein, and the apomorphine-induced rotations were also observed to measure manganese-induced Daergic neurotoxicity. a Effect of wortmannin on autophagy. b, $\mathbf{c}$ Densitometry analysis of Beclin 1 protein levels and LC3 II levels relative to LC3 I (mean $\pm \mathrm{SD}$; one-way ANOVA with Newman-Keuls post hoc analysis, $* p<0.05$ and $* * p<0.01$ ). d Quantitative analysis of the effect of autophagy inhibition before

previously reported to be axonally transported in the GABAergic and DAergic nigrostriatal pathways (Liu et al. 2009; Zhao et al. 2009), the caudate putamen has been targeted as the primary site of Mn injection and the ensuing damage to the nigrostriatal DAergic pathway.

Autophagy is a general term for pathways by which cytoplasmic materials, including soluble macromolecules and organelles, are delivered to lysosomes for degradation (Levine et al. 2011). Autophagy is induced by a variety of stress stimuli, including nutrient and energy stress, ER stress, pathogen-associated molecular patterns and stress-associated molecular patterns, hypoxia, redox changes, and mitochondrial damages (Kroemer et al. 2010). The importance of autophagy to neurons has only been demonstrated recently (Mizushima et al. 2008). For example, mice lacking brain expression of Atg5 or Atg7 rapidly develop neurodegenerative phenotypes (Hara et al. 2006; Komatsu et al. 2006), indicating a neuroprotective role of autophagy. In addition, it
Mn exposure on the apomorphine-induced rotations. e Effect of autophagy inhibition on manganese-induced TH-immunoreactivity change. $f$ Quantitative analysis of the effect of autophagy inhibition on manganese-induced loss of DAergic neurons. $* p<0.05, * * p<0.01$ compared with control groups, scale bar indicates $200 \mu \mathrm{m}$. g The inhibition of autophagy by wortmannin promotes the short-term effect of manganese on TH expression. $\mathbf{h}$ Densitometry analysis of TH levels relative to $\beta$-actin was performed after three independent experiments. i Effect of autophagy inhibition on manganese-induced dopamine levels change (mean \pm SD; one-way ANOVA with Newman-Keuls post hoc analysis, $* p<0.05$ and $* * p<0.01$ )

has been reported that in early Alzheimer's disease, the expression of the autophagy-related protein Beclin 1 is significantly reduced (Pickford et al. 2008). However, contradictory results have also been reported, as evidenced by the accumulation of autophagosomes in brain tissues of patients with Alzheimer's disease (Nixon et al. 2005) and in a model of Huntington's disease (Kegel et al. 2000). Therefore, in this study, we investigated the effect of Mn on autophagy and the role of its dysregulation in Mn-induced DAergic neuronal injury.

Our results showed that different time points $(4 \mathrm{~h}, 8 \mathrm{~h}$, $12 \mathrm{~h}, 1,7,14$, and 28 days) after a single intrastriatal injection of $\mathrm{Mn}$ in rats, apomorphine-induced rotations were significantly increased. In order to expound the behavior change after injection of $\mathrm{Mn}$ in rats, we tested the dopamine levels, DA receptor and TH protein expression after Mn injection. It had been proved that dopamine levels decreased in the basal ganglia of monkey intoxicated with manganese 
and in rat striatum directly injected with manganese(Bird et al. 1984; Lista et al. 1986), our experimental results also proved that the dopamine levels and DA receptor protein expression were significantly decreased (Figs. 1, 2). Furthermore, TH-immunoreactivity of DAergic neurons and TH protein expression were significantly inhibited by Mn 1, 7, 14, and 28 days after the injection (Fig. 3). These results suggested that Mn exposure-affected dopamine levels and DA receptor expression, and leaded to the change of behaviors. As the extension of Mn exposure, Mn-caused irreversible damage to the DAergic neurons, reduced dopamine levels and $\mathrm{D}_{1}$ dopamine receptor expression, consequently influenced motion behaviors. These changes were accompanied by decreased number of autophagic vacuoles and increased number of dysfunctional lysosomes as noted by TEM (Fig. 4). Beclin1, a 60 -kDa coiled-coil protein, is a Bcl-2-interacting cellular protein (LIANG et al. 1998) and a central regulator of autophagy nucleation and induction (Kroemer et al. 2010). Under stress condition, Beclin1 is activated by PI3KIII, resulting in the formation of autophagic vacuoles. Upon induction of autophagy, the microtubuleassociated protein $1 \mathrm{LC} 3$ is recruited to the membrane and lipidated with phosphatidylethanolamine to form LC3-II, a fast migrating form distinct from a cytosolic LC3-I form (Kabeya et al. 2000). LC3-II is located at specific sites in the inner and outer membranes of autophagasomes during early periods of autophagy and is essential for autophagosome formation (Kabeya et al. 2000). Thus, the ratio of LC3 II to LC3 I is used as a marker for autophagy induction. Our results showed that short-Mn exposure compensatorily increased Beclin1 protein expression and decreased ratio of LC3 II to LC3 I, suggesting the inhibited autophagy after long-term $\mathrm{Mn}$ exposure. The data demonstrated that $\mathrm{Mn}$ induced DAergic neurodegeneration was associated with the inhibition of autophagy (Fig. 4).

It is well established that mTOR kinase, which integrates upstream signaling pathways, serves as a key signaling molecule in the suppression of autophagy (Mathew et al. 2007; Jung et al. 2010; Neufeld 2010). It has also been reported that the inhibition of p70S6K, a downstream target of mTOR signal, is involved in the enhancement of autophagy (Saiki et al. 2011). In order to test whether the inhibition of autophagy is dependent on the activation of mTOR and p70S6K signaling, phosphorylation levels of these kinases were evaluated, pursuant to $\mathrm{Mn}$ injection. As expected, 1-28 days after Mn exposure, both mTOR and p70s6K were significantly activated (Fig. 5d). Since the activated mTOR and p70s6K signaling are involved in the inhibition of autophagy (Saiki et al. 2011), it likely the activation of mTOR and p70S6K signaling, at least partly, was responsible for Mn-induced inhibition of autophagy.
Autophagy always represents an adaptative process, affording rapid protection against insults and stress. Accordingly, in this study, the early effects $(<12 \mathrm{~h})$ of Mn on autophagy were also examined. 4-12 h after Mn injection, autophagy was significantly activated, as evidenced by increased number of autophagosome and increased expression of Beclin1 and LC3 II (Fig. 4). These effects occurred concomitantly with the inhibition of mTOR/p70S6K signaling, the latter was likely responsible for the initiation of autophagy. Other reports have indicated that autophagosome formation requires PI3K activity and that PI3K inhibitors, such as wortmannin, LY294002, and 3-MA are typical autophagy inhibitors (Blommaart et al. 1997, Itakura et al. 2008, Matsunaga et al. 2009). TH-immunoreactivity and TH protein expression were not altered by intrastriatal $\mathrm{Mn}$ injection after short-term exposure $(4,8$, and $12 \mathrm{~h})$, but $\mathrm{Mn}$ induced the down-regulation of dopamine level and $\mathrm{D}_{1}$ dopamine receptor expression, co-inhibition of the class III PI3K/ Beclin 1 by pre-treatment with wortmannin significantly inhibited TH-immunoreactivity and $\mathrm{TH} / \mathrm{Neu}$ ratio in the $\mathrm{SNpc}$ of the rats exposed to $\mathrm{Mn}$. In addition, pretreatment with wortmannin significantly reduced the dopamine levels and increased apomorphine-induced rotations in rats exposed to $\mathrm{Mn}$, suggesting that in the early periods post Mn exposure, activated autophagy (Fig. 6) may be compensatorily against neurotoxicities associated with Mn (Fig. 5).

The exact role of dysregulated autophagy in various diseases has yet to be delineated. Notably, as of date, with the exception of this study, no others have assessed the role of autophagy in Mn-induced neurotoxicity. Herein, we demonstrated that a single injection of $\mathrm{Mn}$ in rats led to DAergic neurodegeneration and abnormal apomorphine-induced behaviors 1-28 days after injection. Concomitant with these effects, Mn led to the inhibition of autophagy. In contrast, at earlier time-points post injection (4-12 h), autophagy was activated by Mn, likely reflecting transient protection against Mn-induced DAergic neurodegeneration. In conclusion, these data shed novel information on the role of dysregulation of autophagy in Mninduced neurodegeneration, which may be pharmacologically target to ameliorate the aberrant effects of this metal.

Acknowledgments This study was supported by National Natural Science Foundation of China (81230063, 30800898, 30972499, 81001256); Program for New Century Excellent Talents in University (NCET-09-0846); Key Project of Natural Science Foundation of China (30830087); and Program for Changjiang Scholars and Innovative Research Team in University (PCSIRT).

Conflict of interest There are no financial or other interests with regard to the paper that represent a conflict of interest.

Open Access This article is distributed under the terms of the Creative Commons Attribution License which permits any use, distribution, and reproduction in any medium, provided the original author(s) and the source are credited. 


\section{References}

Alirezaei M, Kemball CC, Whitton JL (2011) Autophagy, inflammation and neurodegenerative disease. Eur J Neurosci 33:197-204

Aschner M, Guilarte TR, Schneider JS, Zheng W (2007) Manganese: recent advances in understanding its transport and neurotoxicity. Toxicol Appl Pharmacol 221:131-147

Benedetto A, Au C, Avila DS, Milatovic D, Aschner M (2010) Extracellular dopamine potentiates mn-induced oxidative stress, lifespan reduction, and dopaminergic neurodegeneration in a BLI3-dependent manner in Caenorhabditis elegans. PLoS Genet 6

Bird ED, Anton AH, Bullock B (1984) The effect of manganese inhalation on basal ganglia dopamine concentrations in rhesus monkey. Neurotoxicology 5:59-65

Blommaart EFC, Krause U, Schellens JPM, Vreeling-Sindelárová H, Meijer AJ (1997) The phosphatidylinositol 3-kinase inhibitors wortmannin and LY294002 inhibit autophagy in isolated rat hepatocytes. Eur J Biochem 243:240-246

Bs L, Wj N (2003) Neurologic effects of manganese: a review. Int J Occup Environ Heal 9:153-163

Carl GF, Blackwell LK, Barnett FC, Thompson LA, Rissinger CJ, Olin KL, Critchfield JW, Keen CL, Gallagher BB (1993) Manganese and epilepsy: brain glutamine synthetase and liver arginase activities in genetically epilepsy prone and chronically seizured rats. Epilepsia 34:441-446

Chen Y, Klionsky DJ (2011) The regulation of autophagyunanswered questions. J Cell Sci 124:161-170

Couper J (1837) On the effects of black oxide of manganese when inhaled into the lungs. Br Ann Med Pharm 1:41-42

Fan QW, Weiss WA (2011) Autophagy and Akt promote survival in glioma. Autophagy 7:536-538

Hara T, Nakamura K, Matsui M, Yamamoto A, Nakahara Y, SuzukiMigishima R, Yokoyama M, Mishima K, Saito I, Okano H, Mizushima N (2006) Suppression of basal autophagy in neural cells causes neurodegenerative disease in mice. Nature 441:885-889

Hearn AS, Stroupe ME, Cabelli DE, Ramilo CA, Luba JP, Tainer JA, Nick HS, Silverman DN (2003) Catalytic and structural effects of amino acid substitution at histidine 30 in human manganese superoxide dismutase: insertion of valine $\mathrm{C}$ gamma into the substrate access channel. Biochemistry-Us 42:2781-2789

Iravani MM, Kashefi K, Mander P, Rose S, Jenner P (2002) Involvement of inducible nitric oxide synthase in inflammation-induced dopaminergic neurodegeneration. Neuroscience 110:49-58

Iravani MM, Leung CC, Sadeghian M, Haddon CO, Rose S, Jenner P (2005) The acute and the long-term effects of nigral lipopolysaccharide administration on dopaminergic dysfunction and glial cell activation. Eur J Neurosci 22:317-330

Itakura E, Kishi C, Inoue K, Mizushima N (2008) Beclin 1 forms two distinct phosphatidylinositol 3-kinase complexes with mammalian Atg14 and UVRAG. Mol Biol Cell 19:5360-5372

Johnson F, Giulivi C (2005) Superoxide dismutases and their impact upon human health. Mol Aspect Med 26:340-352

Jung CH, Ro SH, Cao J, Otto NM, Kim DH (2010) mTOR regulation of autophagy. FEBS Lett 584:1287-1295

Kabeya Y, Mizushima N, Ueno T, Yamamoto A, Kirisako T, Noda T, Kominami E, Ohsumi Y, Yoshimori T (2000) LC3, a mammalian homologue of yeast Apg8p, is localized in autophagosome membranes after processing. EMBO J 19:5720-5728

Keen CL, Ensunsa JL, Clegg MS (2000) Manganese metabolism in animals and humans including the toxicity of manganese. Met Ions Biol Syst 37:89-121

Kegel K, Kim M, Sapp E, McIntyre C, Castano J, Aronin N, DiFiglia M (2000) Huntingtin expression stimulates endosomal-lysosomal activity, endosome tubulation, and autophagy. J Neurosci 20:7268-7278
Komatsu M, Waguri S, Chiba T, Murata S, Iwata J, Tanida I, Ueno T, Koike M, Uchiyama Y, Kominami E, Tanaka K (2006) Loss of autophagy in the central nervous system causes neurodegeneration in mice. Nature 441:880-884

Kroemer G, Marin G, Levine B (2010) Autophagy and the integrated stress response. Mol Cell 40:280-293

Kruger U, Wang Y, Kumar S, Mandelkow EM (2011) Autophagic degradation of tau in primary neurons and its enhancement by trehalose. Neurobiol Aging

Levine B, Mizushima N, Virgin HW (2011) Autophagy in immunity and inflammation. Nature 469:323-335

Levy BS, Nassetta WJ (2003) Neurologic effects of manganese in humans: a review. Int J Occup Environ Health 9:153-163

Li XJ, Li S (2011) Proteasomal dysfunction in aging and Huntington disease. Neurobiol Dis 43:4-8

Liang XH, Kleeman LK, Jiang HH, Gordon G, Goldman JE, Berry G, Herman B, Levine B (1998) Protection against Fatal Sindbis Virus Encephalitis by Beclin, a Novel Bcl-2-Interacting Protein. J Virol 72:8586-8596

Lista A, Abarca J, Ramos C, Daniels AJ (1986) Rat striatal dopamine and tetrahydrobiopterin content following an intrastriatal injection of manganese chloride. Life Sci 38:2121-2127

Liu M, Cai T, Zhao F, Zheng G, Wang Q, Chen Y, Huang C, Luo W, Chen J (2009) Effect of microglia activation on dopaminergic neuronal injury induced by manganese, and its possible mechanism. Neurotox Res 16:42-49

Mandel RJ (2000) Effect of acute -dopa pretreatment on apomorphine-induced rotational behavior in a rat model of Parkinson's disease. Exp Neurol 161:212-219

Mathew R, Karantza-Wadsworth V, White E (2007) Role of autophagy in cancer. Nat Rev Cancer 7:961-967

Matsunaga K, Saitoh T, Tabata K, Omori H, Satoh T, Kurotori N, Maejima I, Shirahama-Noda K, Ichimura T, Isobe T (2009) Two Beclin 1-binding proteins, Atg14L and Rubicon, reciprocally regulate autophagy at different stages. Nat Cell Biol 11:385-396

McKinney AM, Filice RW, Teksam M, Casey S, Truwit C, Clark HB, Woon C, Liu HY (2004) Diffusion abnormalities of the globi pallidi in manganese neurotoxicity. Neuroradiology 46:291-295

Mizushima N, Levine B, Cuervo AM, Klionsky DJ (2008) Autophagy fights disease through cellular self-digestion. Nature 451:10691075

Mizushima N, Yoshimori T, Levine B (2010) Methods in mammalian autophagy research. Cell 140:313-326

Neufeld T (2010) TOR-dependent control of autophagy: biting the hand that feeds. Curr Opin Cell Biol 22:157-168

Newland MC, Ceckler TL, Kordower JH, Weiss B (1989) Visualizing manganese in the primate basal ganglia with magnetic resonance imaging. Exp Neurol 106:251-258

Nixon R, Wegiel J, Kumar A, Yu W, Peterhoff C, Cataldo A, Cuervo A (2005) Extensive involvement of autophagy in Alzheimer disease: an immuno-electron microscopy study. J Neuropathol Exp Neurol 64:113-122

Pickford F, Masliah E, Britschgi M, Lucin K, Narasimhan R, Jaeger P, Small S, Spencer B, Rockenstein E, Levine B, Wyss-Coray T (2008) The autophagy-related protein beclin 1 shows reduced expression in early Alzheimer disease and regulates amyloid beta accumulation in mice. J Clin Invest 118:2190-2199

Racette BA, Aschner M, Guilarte TR, Dydak U, Criswell SR, Zheng W (2011) Pathophysiology of manganese-associated neurotoxicity. Neurotoxicology

Saiki S, Sasazawa Y, Imamichi Y, Kawajiri S, Fujimaki T, Tanida I, Kobayashi H, Sato F, Sato S, Ishikawa K, Imoto M, Hattori N (2011) Caffeine induces apoptosis by enhancement of autophagy via PI3K/Akt/mTOR/p70S6K inhibition. Autophagy 7:176-187 
Santamaria A, Cushing C, Antonini J, Finley B, Mowat F (2007) State-of-the-science review: does manganese exposure during welding pose a neurological risk? J Toxicol Environ Health B Crit Rev 10:417-465

Takeda A (2003) Manganese action in brain function. Brain Res Rev 41:79-87

Ungerstedt U (1971) Postsynaptic supersensitivity after 6-hydroxydopamine induced degeneration of the nigro-striatal dopamine system. Acta Physiol Scand Suppl 367:69-93

Wang X, Liu JZ, Hu JX, Wu H, Li YL, Chen HL, Bai H, Hai CX (2011) ROS-activated p38 MAPK/ERK-Akt cascade plays a central role in palmitic acid-stimulated hepatocyte proliferation. Free Radical Bio Med 51:539-551
Ye Y, Liu J, Xu J, Sun L, Chen M, Lan M (2010) Nano-SiO2 induces apoptosis via activation of $\mathrm{p} 53$ and Bax mediated by oxidative stress in human hepatic cell line. Toxicol In Vitro 24:751-758

Zhang P, Wong TA, Lokuta KM, Turner DE, Vujisic K, Liu B (2009) Microglia enhance manganese chloride-induced dopaminergic neurodegeneration: role of free radical generation. Exp Neurol 217:219-230

Zhao F, Cai T, Liu M, Zheng G, Luo W, Chen J (2009) Manganese induces dopaminergic neurodegeneration via microglial activation in a rat model of manganism. Toxicol Sci 107:156-164 